\title{
The positive effect of tenting screws for primary horizontal guided bone regeneration: A retrospective study based on cone-beam computed tomography data
}

\author{
César Neto, João B ; Cavalcanti, Marília C ; Sapata, Vitor M ; Pannuti, Cláudio M ; Hämmerle,
} Christoph H F ; Naenni, Nadja ; Thoma, Daniel S ; Romito, Giuseppe A

\begin{abstract}
Objectives: To radiographically evaluate the effect of the adjunctive use of tenting screws (TS) for primary horizontal guided bone regeneration (GBR). Materials methods: Twenty-eight patients in need of staged bone augmentation were consecutively treated in a private practice. A xenogenic particulate bone substitute material (DBBM) and a resorbable collagen membrane were used in all patients. Subjects were divided into two groups: control (conventional GBR; $\mathrm{n}=22$ ) and test (tenting screws in conjunction with GBR - TS; $\mathrm{n}=22$ ). CBCT images were obtained before augmentation and after 6-8 months. CBCTs were superimposed, and linear horizontal measurements were performed. Alveolar ridge width (RW) and ridge width change (RWchange) were assessed at 1, 3, 5, and $7 \mathrm{~mm}$ below the bone crest. Results: Forty-four sites in 28 patients were evaluated. No differences between the groups were detected for RW at baseline (TS: $5.87 \pm 2.41$; control: $5.36 \pm 1.65$ ). Regarding RWchange, TS promoted an additional effect at 1 and $3 \mathrm{~mm}$ below the crest compared to control $(\mathrm{p}<.05$; RWchange- 1 TS: $3.72 \pm 2.46$; control: $1.25 \pm 3.05$; RWchange-3 TS: $3.98 \pm 2.53$; control: $2.50 \pm 2.02$ ). The final RW was greater in group TS compared to the control group at the 1,3 , and $5 \mathrm{~mm}$ level $(\mathrm{p}<.05)$. Conclusions: The use of tenting screws exerted a positive effect on staged GBR with a greater final RW at the $3 \mathrm{~mm}$ level. In addition, GBR in conjunction with TS was able to provide consistent bone augmentation at lingual/palatal sites. Keywords: alveolar ridge augmentation; bone regeneration; cone-beam computed tomography; dental implants.
\end{abstract}

DOI: https://doi.org/10.1111/clr.13630

Posted at the Zurich Open Repository and Archive, University of Zurich

ZORA URL: https://doi.org/10.5167/uzh-190169

Journal Article

Accepted Version

Originally published at:

César Neto, João B; Cavalcanti, Marília C; Sapata, Vitor M; Pannuti, Cláudio M; Hämmerle, Christoph H F; Naenni, Nadja; Thoma, Daniel S; Romito, Giuseppe A (2020). The positive effect of tenting screws for primary horizontal guided bone regeneration: A retrospective study based on cone-beam computed tomography data. Clinical Oral Implants Research, 31(9):846-855.

DOI: https://doi.org/10.1111/clr.13630 
DR. JOÃO BATISTA CESAR NETO (Orcid ID : 0000-0002-6823-6170)

PROF. CHRISTOPH H.F. HÄMMERLE (Orcid ID : 0000-0002-8280-7347)

Article type : Original Research

The positive effect of tenting screws for primary horizontal guided bone regeneration: a retrospective study based on cone-beam computed tomography data.

Running title: Effect of tenting screws on guided bone regeneration

João Batista César Neto ${ }^{1}$, Marília C. Cavalcanti ${ }^{1}$, Vitor M. Sapata ${ }^{1}$, Cláudio M. Pannuti ${ }^{1}$, Christoph H.F. Hämmerle², Nadja Naenni², Daniel S. Thoma², Giuseppe A. Romito¹.

${ }^{1}$ Division of Periodontology, School of Dentistry, University of São Paulo, São Paulo, Brazil

${ }^{2}$ Clinic of Reconstructive Dentistry, Center of Dental Medicine, University of Zurich, Zurich, Switzerland

Acknowledgments: The authors thank Dr. Fausto Medeiros Mendes for the multilevel regression analysis. This study was financed in part by the Coordenação de Aperfeiçoamento de Pessoal de Nivel Superior-Brasil (CAPES)-Finance Code 001. The study was supported by the Division of Periodontology, College of Dentistry, University of São Paulo, São Paulo, Brazil.

Author contributions: César Neto JB conceived the idea, performed all surgeries and led writing; Cavalcanti MC and Sapata VM superimposed and performed measurements of the CBCT scans and led writing; Romito GA, Naenni N, Thoma DS and Christoph H.F. Hämmerle led writing, Pannuti CM and Cavalcanti MC ran statistical analysis.

Address for correspondence:

João Batista César Neto, Prof. Dr.

Division of Periodontology, School of Dentistry, University of São Paulo

This article has been accepted for publication and undergone full peer review but has not been through the copyediting, typesetting, pagination and proofreading process, which may lead to differences between this version and the Version of Record. Please cite this article as doi: $\underline{10.1111 / C L R .13630}$

This article is protected by copyright. All rights reserved 
Av. Prof. Lineu Prestes, 2227, Cidade Universitária, São Paulo-SP, Brazil.

05508-000

Phone/fax: $55113091-7833$

Email: jbcesarneto@usp.br

\section{Abstract}

Objectives: to radiographically evaluate the effect of the adjunctive use of tenting screws (TS) for primary horizontal guided bone regeneration (GBR).

Materials \& Methods: 28 patients in need of staged bone augmentation were consecutively treated in a private practice. A xenogenic particulate bone substitute material (DBBM) and a resorbable collagen membrane were used in all patients. Subjects were divided into two groups: control (conventional GBR; $n=22$ ) and test (tenting screws in conjunction with GBR - TS; $n=$ 22). СВСТ images were obtained before augmentation and after 6-8 months. CВCTs were superimposed and linear horizontal measurements were performed. Alveolar ridge width (RW) and Ridge width change (RWchange) were assessed at 1, 3, 5 and 7 millimeters below the bone crest.

Results: Forty-four sites in 28 patients were evaluated. No differences between the groups were detected for RW at baseline (TS: $5.87 \pm 2.41$; control: $5.36 \pm 1.65$ ). Regarding RWchange, TS promoted an additional effect at 1 and $3 \mathrm{~mm}$ below the crest compared to control $(p<0.05)$ (RWchange-1 TS: $3.72 \pm 2.46$; control: $1.25 \pm 3.05$; RWchange-3 TS: $3.98 \pm 2.53$; control: $2.50 \pm$ 2.02). The final RW was greater in group TS compared to the control group at the 1,3 and $5 \mathrm{~mm}$ level $(p<0.05)$.

Conclusions: The use of tenting screws exerted a positive effect on staged GBR with a greater final RW at the $3 \mathrm{~mm}$ level. In addition, GBR in conjunction with TS was able to provide consistent bone augmentation at lingual/palatal sites.

Key words (MeSH terms): bone regeneration; alveolar ridge augmentation; dental implants; cone-beam computed tomography; 


\section{INTRODUCTION}

The healing process of the alveolar ridge after tooth loss is followed by dimensional changes in both soft and hard tissue that may jeopardize a prosthetically ideal implant positioning. These dimensional changes occur predominantly during the first 3 months after extraction (Schropp et al., 2003) and are more pronounced at the buccal aspect of the ridge (Araújo \& Lindhe, 2005). After 6 months, up 29 to $63 \%$ loss in width and 11 to $22 \%$ loss in height can be expected (Tan et al., 2012). Long-term clinical studies even showed up to $50 \%$ of horizontal bone loss after 12 months (Schropp et al., 2003) and 40 to $60 \%$ of total ridge resorption 3 years after tooth loss (Ashman, 2000). Although ridge preservation procedures aiming at minimizing these dimensional changes of the alveolar ridge exist and are heavily investigated, they cannot fully prevent ridge remodeling (Jung et al., 2013; Llanos et al., 2019).

Insufficient bone volume after alveolar healing is a clinical challenge that increases the complexity or even makes implant-supported restorations impossible. Guided bone regeneration (GBR) is one of the most common regenerative techniques applied to reconstruct alveolar bone.

It shows good predictability and high survival rates of implants placed after augmentation (Hämmerle et al., 2002). 
The biological concept of GBR employs a membrane as a physiological barrier to protect the blood clot formed underneath to heal with minimal interference of connective and epithelial cell ingrowth (Dahlin et al., 1989; Dahlin et al., 1990, Schenk et al., 1994). The success of GBR further depends on space maintenance to allow blood clot formation and colonization of osteoprogenitor cells (Schenk et al., 1994). A large body of evidence exists on the use of the most commonly used resorbable collagen membranes for GBR procedures (Pitaru et al. 1987; Zitzmann et al. 1997, 2001; Hockers et al. 1999; Friedmann et al. 2001; Hammerle \& Lang 2001). However, if not supported by bone or bone substitute material, they are prone to collapse and will thus impair space maintenance and clot formation (Chasioti et al., 2013). Several biomaterials have been investigated to support the membrane as an attempt to overcome such limitation. Despite the improvement promoted by granulated biomaterials, it is still difficult to avoid particle displacement during flap management and suturing (Mir-Mari et al., 2016). In this sense, new biomaterials (such as collagenated ones), biologics and modifications of the original technique were proposed to increase bone gain after GBR procedure (Elgali et al., 2017).

The use of tenting screws has been proposed as an adjunct device for GBR in case reports, case series and in a retrospective cohort study (Buser et al., 1993; Becker et al., 1994; Mengel et al., 2005; Simion et al., 2010; Chasioti et al., 2013, Deeb et al., 2017). According to these studies, tenting screws may prevent from membrane collapse, protect the augmented site against mechanical influence and favor the stability of the underlying bone or bone substitute material. However, such studies do not provide a direct estimation of the additional benefit tenting screws may have on bone augmentation. The lack of controlled studies using reliable methodologies for bone gain analysis make it difficult to establish clinical guidelines for the use of tenting screw in daily practice.

Therefore, the aim of the present study was to radiographically evaluate the adjunctive effect of the use of tenting screws on the horizontal linear changes after GBR in bone deficient sites of healed ridges.

\section{MATERIAL AND METHODS}

\section{Study design}

Cone-beam computer tomography (CBCT) scans from consecutively treated patients were retrospectively analyzed. The criteria to indicate GBR was the same for both groups and no additional criteria was employed to indicate the use of tenting screws. Scans from a group (Control) of patients who were treated with a classical guided bone regeneration (GBR) were 
compared with a group (Test), where tenting screws (TS) had simultaneously been applied with a GBR procedure.

Radiographs were analyzed before and after primary bone augmentation. The study protocol was approved by the Ethical Review Board of the Dental School, University of São Paulo $\left(n^{\circ} 2.798 .914\right)$.

\section{Study population}

The subjects involved in this study underwent bone grafting in a private practice in Sorocaba, São Paulo, Brazil, between 2013 and 2018. All patients were scheduled for implantsupported rehabilitation at edentulous sites. Patients were included if the diagnostic CBCT indicated the need of a primary GBR procedure in order to allow for implant placement in a prosthetically correct position. After 6 to 8 months of the regenerative procedure, a second CBCT scan was obtained to evaluate bone change and plan implant placement.

\section{Eligibility criteria}

Inclusion criteria: systemically healthy patients (American Society of Anesthesiologists ASA I and II); older than 18 years; under periodontal maintenance (bleeding on probing and plaque index < 20\%); at least one site per candidate planned for implant-supported rehabilitation exhibiting less than $4 \mathrm{~mm}$ of bone width at $1 \mathrm{~mm}$ below the bone crest or in need of bone reconstruction as diagnosed at the time of digital implant planning (i.e. GBR was considered necessary when baseline ridge width did not allow for a screw-retained restoration without the use angled abutments or tilted implants); CBCT scan before and after bone augmentation with good accuracy for adequate assessment.

Exclusion criteria: ongoing periodontal disease; pregnant or lactating women; smokers ( $>10$ cigarettes/day); existence of a bone metabolic disease; currently taking drugs that might influence bone metabolism; use of bisphosphonates in the last 4 years; history of malignancy, radiotherapy or chemotherapy for malignancy in the past 5 years.

\section{Surgical procedures}

All patients received a single dose of steroid anti-inflammatory (4mg of dexamethasone EMS, Brazil) and $2 \mathrm{~g}$ of amoxicillin EMS, Brazil) 1 hour before surgery. A single operator (J.B.C.N) performed all surgeries under local anesthesia. Full-thickness trapezoidal flaps were used for anterior sites with a linear incision placed at the mid-crest and two releasing incisions one tooth away from the bone defect (Fig. 1a). A similar design was adopted for posterior areas except for 
the distal release incision, which was performed only when considered necessary. All soft tissue remnants were removed from the underlying bone. Multiple perforations of the buccal cortical plate were performed with spherical drills under copious irrigation with saline solution (Fig. 1a). In both groups, bone defects were grafted applying the same biomaterials. Deproteinized bovine bone mineral (DBBM - Geistlich Bio-Oss ${ }^{\circledR}$, Geistlich Pharma AG, Switzerland) mixed with autogenous chips harvested from adjacent sites. Bone deficiencies were mostly on the buccal aspect, but, when necessary, lingual and palatal sites were also grafted to allow the implant placement in a prosthetically driven position. Bone augmentation was covered with a collagen membrane of porcine origin (Geistlich Bio-Gide®, Geistlich Pharma AG, Switzerland) (Fig 1c) (Control). In the test group, adjunctive tenting screws (TS) with a length of 8 or $10 \mathrm{~mm}$ and a diameter of $1.5 \mathrm{~mm}$ and a $3.5 \mathrm{~mm}$ head diameter (fixing screw, Neodent $囚$, Curitiba, Brazil) were applied. TS were inserted only buccally at the center of the horizontal defect with the coronal portion of the screw head $1 \mathrm{~mm}$ apical of the top of the ridge and $4 \mathrm{~mm}$ away from the buccal bone (Fig. 1b). In both groups periosteal releasing incisions were performed at the buccal aspect in order to allow for primary and tension-free wound closure. In lower posterior cases blunt dissection was applied at the lingual to facilitate wound closure. Flaps were adapted with simple interrupted sutures placed at the releasing and horizontal incisions. Horizontal mattress sutures were placed in the horizontal incision. The final closure was achieved with simple interrupted sutures in the horizontal incision (Fig 1d). It is important to emphasize that the objective of flap design, incisions and sutures were to achieve a tension free closure in order to avoid flap dehiscence and tearing, thus increasing the chances for success in the regenerative procedure.

Patients were prescribed the following drugs for post-surgical intake: Amoxicillin $875 \mathrm{mg}$ (EMS, Brazil) twice a day, for 7 days; nimesulide 100mg (EMS, Brazil) twice a day for 3 days; sodium dipyrone 500mg (Ache, Brazil) every 6 hours, for 2 days; chlorhexidine digluconate rinsing $0.12 \%$ (Colgate-Palmolive, Brazil) 3 times a day for 21 days were prescribed for postoperative infection and pain control. Sutures were removed 14 to 21 days after surgery.

\section{Clinical evaluation}

Patients were recalled weekly during the first month of follow-up. At these appointments frequency, time and magnitude of membrane and tenting screws exposure were recorded.

\section{Radiographic analysis}

All CBCTs were obtained before and 6-8 months after the surgical procedure. The acquisition of the images was made by an iCAT Classic ${ }^{\circledR}$ unit (Imaging Sciences, Kavo, USA) with the following protocol: work scheme of $120 \mathrm{kV}$ acceleration voltage and 3 to $7 \mathrm{~mA}$ beam 
current; scan time of 40 seconds; flat panel amorphous silico sensor; field-of-view size of $6 \times 16$ $\mathrm{cm}$; $360^{\circ}$ rotation; 14 bits gray scale and voxel size of $0.25 \mathrm{~mm}$. An open source software (3D Slicer 4.5, www.slicer.org) was used to process the Digital Imaging and Communications in Medicine (DICOM) files. Anatomical structures (i.e. the cranial base and the nasal septum) were used for registration (superimposition). The DICOM files were segmented and the region of interest (ROI) was cropped in both datasets. The datasets were manually superimposed and the software performed the final automatic registration. The central region of the bone defect was subsequently selected for analysis on the 3D reconstruction (sagital, axial and coronal views). An image file of the superimposed scans was exported to an image-editing software (Pixelmator, version 3.8.1 Phoenix 90618.1654). A baseline grid was drawn onto the baseline image with the following reference lines: vertical line $(\mathrm{VL})$ at the bucco-oral center of the ridge (in cases where ridge anatomy hampers the definition of the center, the first third of the ridge will be used as reference); horizontal lines perpendicular to $\mathrm{VL}$ at five different levels (at bone crest, $1 \mathrm{~mm}, 3 \mathrm{~mm}$, $5 \mathrm{~mm}$ and $7 \mathrm{~mm}$ apical of the bone crest) (Fig. 2).

The outcome variables were:

- Ridge width (RW) at four levels (1, 3, 5 and $7 \mathrm{~mm}$ apical of the bone crest): RW1, RW3, RW5, RW7, before and after augmentation.

- Horizontal ridge width change (RWchange): difference between RW at baseline and 6 to 8 months after augmentation at each of the four levels, RWchange-1, RWchange-3, RWchange-5 and RWchange-7. RWchange $1 \mathrm{~mm}$ apical of the crest was considered the primary outcome. The overall results are the average of the four height levels analyzed.

These measurements were performed both at the buccal and lingual/palatal aspect of each augmented site (Fig. 2). The horizontal line drawn at the level of the bone crest and the vertical line $(V L)$ were used to detect horizontal resorption as well as the degree of vertical crestal resorption. Vertical change was considered resorption when bone level after augmentation was apical to the original bone crest position, and gain was considered when bone level was coronal to the bone crest (Fig. 2). Additionally, performance of conventional GBR at the palatal/lingual aspect was evaluated (secondary outcome).

All CBCT measurements were performed by a single, calibrated examiner. Intra-observer reliability was determined by repeating measurements in 10 randomly selected CBCT scans (5 of each group) with a one-week interval between the first and second evaluations.

\section{Sample size calculation}

Sample size calculation was performed with data from Freitas et al. (2013). Horizontal ridge width change at $1 \mathrm{~mm}$ (RWchange-1) apical of the bone crest was considered the primary 
outcome. Considering $1 \mathrm{~mm}$ as a clinically relevant difference between groups, pooled standard deviation of $0.8 \mathrm{~mm}$, a two-tailed independent t-test was performed with alpha $5 \%$ and $80 \%$ of power. Considering a $10 \%$ drop out-rate, a total of 34 sites (17 per group), would be necessary to detect a statistically significant difference.

\section{Statistical analysis}

Descriptive statistics were expressed as mean and standard deviation for RW (baseline and follow-up) and horizontal ridge width change. D'Agostino tests were used to verify adherence to the normality curve and Levene test for homoscedasticity. As the data followed a normal distribution, parametric analyses were conducted.

Since some participants contributed with more than one site, comparison between the groups regarding the primary and secondary outcomes were made through multilevel linear regression analysis. A 95\% confidence interval was calculated for the primary outcome and the statistical significance was set at $5 \%$, and a statistical package was used (Stata 13.0, College Station, USA).

Pearson correlation test was used to analyze the correlation of baseline $1^{\text {st }} \mathrm{mm}$ width to vertical crestal resorption.

This study was reported in compliance with STROBE Statement for observational studies.

\section{RESULTS}

The final sample composed of 28 patients and 44 sites (22 in each group). The overall mean age was $54.14 \pm 14.73$ years, ranging from 19 to 79 years (Control $=52.77 \pm 13.09$; Test $=$ $51.95 \pm 18.50$ years;). Females comprised $64.30 \%$ of the study population. In the control group 12 sites were located in the maxilla and 10 in the mandible while for the test group 9 sites were located in the maxilla and 13 in the mandible (Table 1).

For the control group, forty-nine patients were selected from a database and 18 patients with 22 defects fulfilled the eligibility criteria. For the test group 18 patients with 24 defects out of fifty-four patients were treated with a guided bone regeneration procedure (GBR) and adjunct tenting screws between 2013 and 2018. Seven patients had surgery at two different time points and contributed to sites for both groups. However, 2 subjects with 2 defects from the test group 
had to be excluded because matching of the obatined CBCTs was not possible due to artifacts. This resulted in 16 patients and 22 defects in group TS.

\section{General aspects of surgical procedure}

Local swelling was observed in some degree for all patients. One site per group presented minor membrane exposure between the $2^{\text {nd }}$ and $3^{\text {rd }}$ postoperative week. Both sites healed spontaneously after 3 to 4 weeks under 0.12 chlorhexidine rinsing. Temporary sensory loss was reported in 2 cases at lower premolar sites, both at TS group. No tenting screw exposure was observed

\section{Radiographic results}

With respect to ridge width $(\mathrm{RW})$ at baseline, no differences between the groups were detected (Table 2).

Tenting screws exhibited an additional benefit on the total ridge width (RW) at the followup. Significant differences were observed for RW-1, RW-3 and RW-5 at follow-up (Table 3). For the overall results (average of the 4 levels), test group showed a significantly thicker alveolar ridge $(9.47 \pm 2.63 \mathrm{~mm})$ when compared to control group $(7.70 \pm 1.85 \mathrm{~mm})(p=0.010)$. Detailed results for at follow-up are displayed on table 3.

An additional change in horizontal ridge width (RWchange) was observed for group TS at $1 \mathrm{~mm}$ (RWchange-1) and $3 \mathrm{~mm}$ (RWchange-3) below the bone crest $(p=0.001 / 0.020)$, when compared to control group. However, RWchange at $5 \mathrm{~mm}$ and $7 \mathrm{~mm}$ did not exhibit significant differences between the groups (Table 4). The overall mean change (average result of the 4 levels evaluated) for the test group resulted in $3.57 \pm 2.38 \mathrm{~mm}$ and for the control group in $2.35 \pm$ $1.64 \mathrm{~mm}$ (Table 3) ( $p=0.009)$. Horizontal crestal resorption was observed at the first millimeter in 12 sites (mean resorption: $-1.20 \pm 3.80 \mathrm{~mm}$ ) in the control group and in 2 sites in the test group (mean loss: $-1.66 \pm 4.30 \mathrm{~mm}$ ). No correlation between horizontal crestal resorption and horizontal ridge width at baseline was observed $(r=0.04 ; p>0.05)$. Detailed results for all measurements are displayed in Table 3. In addition, vertical crestal resorption was detected in 8 sites of control group $(-1.11 \pm 0.70 \mathrm{~mm})$ and 2 sites of test group $(-0.90 \pm 0.04 \mathrm{~mm})$. An intra-class correlation coefficient of 0.99 was obtained regarding baseline $1^{\text {st }} \mathrm{mm}$ width to vertical crestal resorption.

Regarding the lingual/palatal region, GBR procedure was performed at 19 sites in 10 patients from both groups (10 from TS group and 9 from Control group). A mean lingual/palatal RWchange (LRWchange) of $0.94 \pm 1.00 \mathrm{~mm}$ was observed. The change at $1 \mathrm{~mm}$ reached $0.50 \mathrm{~mm}$ and $1 \mathrm{~mm}$ of LRWchange was achieved at 3, 5 and $7 \mathrm{~mm}$ (Table 5). 
Multilevel linear regression analysis showed that, when comparing all variables for primary outcome (RWchange-1), age, gender and arch (i.e. upper and lower) did not influence data variance (model 2, Table 6). In relation to the groups, the model adjusted for anterior/posterior sites (model 3, Table 6) showed that the test group had, on average, $1.86 \mathrm{~mm}$ more bone gain than the control group $(p<0.001$ ). In relation to anterior/posterior sites, the posterior sites had undergone greater bone gain when compared to the anterior sites $(p<0.001)$, even after the adjustment for groups (Table 6).

\section{DISCUSSION}

The results of the present study demonstrate that the use of tenting screws in conjunction with GBR exerts a positive effect on horizontal ridge width. Such an effect was more pronounced at $3 \mathrm{~mm}$ below the bone crest.

One might speculate that the use of tenting screws give mechanical support for the membrane and thus may lead to increased stability of the graft particles underneath. Previous pre-clinical studies demonstrated that, even with tension-free flap closure, compressive forces at the coronal portion of the augmented site can not totally be avoided during suturing (Mir-Mari et al., 2016) and may lead to the displacement of grafting particles. The results of the control group in the present study corroborate with these pre-clinical findings. A decrease in ridge width at the coronal portion and an increased ridge width at 5 and $7 \mathrm{~mm}$ was observed. In contrast, the use of tenting screws in the test group appeared to have counteracted at least part of the compressive forces, favoring ridge width gain at the coronal aspect in the test group.

A recent systematic review (Naenni et al., 2019) analyzed and compiled the results of prospective studies that compared techniques for primary bone augmentation. The pooled average gain reported for studies that employed radiographic analysis for horizontal bone augmentation was $2.90 \pm 0.83 \mathrm{~mm}$. Using this systematic review as reference, the present control group ended up with values below the average, while the values for the test group showed results above the average. Surprisingly, the minority of studies included in the systematic review performed radiographic evaluation (Antoun et al., 2001; Araújo, 2016; Beitlitum et al., 2010; da Costa et al., 2011; de Freitas et al., 2013; Mazzocco et al., 2011) and none of them have used CBCT superimposition to standardize the region of interest. There is only one study that performed both clinical and radiographic analysis in the same sample (de Freitas et al., 2013). According to the authors of the systematic review, radiographic measurements may be considered more precise compared to clinical ones because of a lower standard deviation. In addition, none of the included studies reported data for the $1 \mathrm{st} \mathrm{mm}$ below the bone crest. A direct 
comparison of the primary outcome of the present investigation with previous reports is not possible due to lack of evidence.

The present study provides a more precise picture of the behavior of grafting material at different levels of the ridge. The CBCT-superimposition and the method of analysis were able to clearly demonstrate the location of ridge width change despite the occurrence of crestal resorption. Depending on the methodology employed for clinical or radiographic assessment of ridge width augmentation, crestal resorption may interfere in these evaluations mainly in cases where the top of the ridge is used as reference for the location of region of interest.

In the present study, vertical crestal resorption of a certain extent was detected in 10 cases ( 8 in the control group and 2 in the test group). The greater frequency of cases exhibiting crestal resorption in the control group may have favored the detection of a significant difference between the groups at $1 \mathrm{~mm}$ below the crest. Most of the existing literature reports on measurements performed the level of $3 \mathrm{~mm}$ below the crest (Naenni et al., 2019). Also, a possible explanation for this finding is that, during surgical procedure, particles were usually placed on top of the ridge as an attempt to correct minor vertical defects and lingual/palatal bone deficiencies. According to the present results it may be hypothesized that the particles placed on top of the ridge may have prevented or counteracted crestal resorption and tenting screws may have favored such a process.

A prospective cohort study (Meloni et al. 2017) presenting most similarities regarding the radiographical analysis with the present case series reported an average horizontal bone gain of $5.03 \pm 2.15 \mathrm{~mm}$ measured $2 \mathrm{~mm}$ below the crest. That study analyzed the performance of GBR with DDBM (deproteinized bovine bone mineral) mixed with $50 \%$ autogenous chips covered with a collagen membrane and stabilized with bone tacks over time. The radiographically measured bone gain change achieved was about $1 \mathrm{~mm}$ greater compared to the one observed at the coronal portion of the present study. Such difference may be explained by the different level of the measurement performed, the higher amount of autogenous bone used by Meloni et al. (2017) and the method of membrane fixation. In addition, the ridge width at baseline is known to influence the magnitude of bone augmentation that can be achieved. According to the findings of Naenni et al. (2017), thinner ridge width at baseline does present with a greater potential of achievable gain when compared to a wider ridge. This is in line with the results of the present study presenting less resorbed ridges at baseline compared to the study by Meloni et al. (2017) and thus resulting in a less pronounced bone gain over time. Despite the present interesting data, it is important to address that both radiographic and clinical measurements are not able to identify the amount of newly formed bone present among graft particles. The association of autogenous bone may have an influence in this sense. However, it is not possible to assure that such 
histological differences might have an impact on long-term performance of implant-supported restorations. Further studies should be conducted to elucidate such questions.

The documentation for the use of tenting screws is still scarcely reported. The present controlled study is the first to radiographically evaluate ridge width change achieved by applying this technique. Most of the existing evidence reports on small case series or case reports (Buser et al., 1993; Becker et al., 1994; Mengel et al., 2005; Simion et al. 2010, Chasioti et al., 2013). There exists only one retrospective comparative cohort study (Deeb et al., 2017) evaluating the influence of tenting screws associated with GBR using collagen membranes. This apporach was compared to a tunnel technique and GBR with PTFE membranes for horizontal ridge augmentation. Authors reported a higher frequency of implant placement after grafting with tenting screws, a lower rate of membrane exposure, graft loss and the need for postoperative visits. Despite the findings showing potential advantages for the use of tenting screws, the absence of a control group and no clinical or radiographic objective measurements of ridge width change may be considered limitations of the aforementioned study.

Another novel result of the present study was the documentation of lingual/palatal bone regeneration. Within the limits of our knowledge, this is the first study that systematically evaluated the average ridge width augmentation that may be achieved in such areas. At the time of digital planning, 19 sites of the present sample were considered eligible for GBR at the lingual/palatal aspect in order to subsequently place an implant in a prosthetic correct position allowing for a screw retention without angled abutments or tilted implants. In case of lingual/palatal GBR, a ridge width change between 0.50 and $1 \mathrm{~mm}$ could be achieved. These results show that it is possible to obtain bone augmentation in such sites. However, this data must carefully be interpreted. Further studies are necessary in order to clarify the potential of GBR in such regions and to set boundaries for its indications and limitations.

The retrospective design and absence of randomization between the treatments may be considered limitations of the present study, some data were not collected in a protocolized manner as it should be in an RCT (i.e., tension free flap closure, patients reporting outcomes), however some positive characteristics may be pointed out as strengths. First, a proper and welldefined control group. Second, the use of CBCT superimposition and a consistent and reproductive measurement method performed by one calibrated examiner. Third, a single experienced operator performed all surgeries. And finally, a sample size per group that is greater than most of bone grafting studies available in the literature (post hoc $n=84 \%$ ). The inclusion of single and multiple sites and anterior and posterior teeth, as well as upper and lower jaws may also be considered a limitation, however the multilevel regression analysis showed that sites 
(anterior compared to posterior sites) and jaws (upper compared to lower jaws) had low influence on data variance, and corresponded to only $10.13 \%$.

Within the limits of the present study it can be concluded that the adjunctive use of tenting screws improved the results of hard tissue regeneration when compared to the conventional GBR technique. Regeneration procedures were more effective mainly at the first 3 millimeters below the crest of the edentulous ridge with the use of tenting screws. These findings support the adjunct use of tenting screws when performing primary bone augmentation procedures. Prospective randomized studies are necessary in order to confirm the trend identified in this retrospective evaluation.

\section{REFERENCES}

Antoun, H., Sitbon, J.M., Martinez, H., Missika, P. (2001). A prospective randomized study comparing two techniques of bone augmentation: onlay graft alone or associated with a membrane. Clinical Oral Implants Research. Dec;12(6):632-9.

Araújo, M. G., \& Lindhe, J. (2005). Dimensional ridge alterations following tooth extraction. An experimental study in the dog. Journal of Clinical Periodontology. Feb;32(2):212-8.

Araújo, P. M. (2016) Análise clínica de substituto ósseo em bloco para aumento horizontal e influência no sucesso dos implantes osseointegrados - estudo em humanos Odontologia do Centro de Ciências Brazil: Saúde da Universidade Federal de Santa Catarina.

Ashman, A. (2000). Postextraction ridge preservation using synthetic alloplast. Implant Dentistry. 9(2):168-76.

Becker, W., Becker, B. E., McGuire, M. K. (1994). Localized ridge augmentation using absorbable pins and e-PTFE barrier membranes: A new surgical technique. Case reports. International Journal of Periodontics and Restorative Dentistry. Feb;14(1):48-61.

Beitlitum, I., Artzi, Z., Nemcovsky, C. E. (2010). Clinical evaluation of particulate allogeneic with and without autogenous bone grafts and resorbable collagen membranes for bone augmentation of atrophic alveolar ridges. Clinical Oral Implants Research. Nov;21(11):1242-50. doi: 10.1111/j.1600-0501.2010.01936.x. 
Buser, D., Dula, K., Belser, U., Hirt, H. P., Berthold, H. (1993). Localized ridge augmentation using guided bone regeneration. 1. Surgical procedure in the maxilla. International Journal of Periodontics and Restorative Dentistry.13:29-45.

Chasioti, E., Chiang, T.F., Drew, H. J. (2013). Maintaining space in localized ridge augmentation using guided bone regeneration with tenting screw technology. Quintessence International. Nov-Dec;44(10):763-71. doi: 10.3290/j.qi.a30178.

da Costa, C. E., Pelegrine, A. A., Fagundes, D. J., Simoes, M de. J., Taha, M. O. (2011). Use of corticocancellous allogeneic bone blocks impregnated with bone marrow aspirate: a clinical, tomographic, and histomorphometric study. General Dentistry. Sep-Oct;59(5):e200-5.

Dahlin, C., Sennerby, L., Lekholm, U., Linde, A., Nyman, S. (1989). Generation of new bone around titanium implants using a membrane technique: an experimental study in rabbits. International Journal of Oral and Maxillofacial Implants. 4(1):19-25.

Dahlin, C., Gottlow, J., Linde, A., Nyman, S. (1990). Healing of maxillary and mandibular bone defects using a membrane technique. An experimental study in monkeys. Scandinavian Journal of Plastic and Reconstrutive Surgery and Hand Surgery. 24(1):13-9.

Deeb, G.R., Tran, D., Carrico, C.K., Block, E., Laskin, D. M., Deeb, J. G. (2017). How effective is the tent screw pole technique compared to other forms of horizontal ridge augmentation? Journal of Oral and Maxillofacial Surgery. Oct;75(10):2093-2098. doi: 10.1016/j.joms.2017.05.037.

de Freitas, R. M., Susin, C., Spin-Neto, R., Marcantonio, C., Wikesjo, U. M., Pereira, L. A., Marcantonio, E Jr. (2013). Horizontal ridge augmentation of the atrophic anterior maxilla using rhBMP-2/ACS or autogenous bone grafts: a proof-of-concept randomized clinical trial. Journal of Clinical Periodontology. Oct;40(10):968-75. doi: 10.1111/jcpe.12148.

Elgali, I., Omar, O., Dahlin, C., Thomsen, P. (2017) Guided bone regeneration: materials and biological mechanisms revisited. European Journal of Oral Sciences. Oct;125(5):315-337. doi: 10.1111/eos.12364. 
Friedmann, A., Strietzel, F.P., Maretzki, B., Pitaru, S. \& Bernimoulin, J.P. (2001) Observations on a new collagen barrier membrane in 16 consecutive treated patients. Clinical and histological findings. Journal of Periodontology 72: 1616-1623.

Hämmerle, C.H.F., Lang, N.P. (2001) Single stage surgery combining transmucosal implant placement with guided bone regeneration and bioresorbable materials. Clinical Oral Implants Research. Feb;12(1):9-18.

Hämmerle, C. H., Jung, R. E., Feloutzis, A. (2002). A systematic review of the survival of implants in bone sites augmented with barrier membranes (guided bone regeneration) in partially edentulous patients. Journal of Clinical Periodontology. 29 Suppl 3:226-31.

Hockers, T., Abensur, D., Valentini, P., Legrand, R. \& Hämmerle, C.H.F. (1999) The combined use of bioresorbable membranes and xenografts or auto-grafts in the treatment of bone defects around implants. A study in beagle dogs. Clinical Oral Implants Research. 10: 487498.

Jung R.E., Philipp A., Annen B.M., Signorelli L., Thoma D.S., Hämmerle C.H.F., et al. (2013) Radiographic evaluation of different techniques for ridge preservation after tooth extraction: a randomized controlled clinical trial. Journal of Clinical Periodontology 40, 90-98.

Llanos, A. H., Sapata, V. M., Jung, R. E., Hämmerle, C. H., Thoma, D. S., César Neto, J. B., Pannuti, C. M., Romito, G. A. (2019) Comparison between two bone substitutes for alveolar ridge preservation after tooth extraction: cone-beam computed tomography results of a non-inferiority randomized controlled trial. Journal of Clinical Periodontology. Mar;46(3):373-381. doi: 10.1111/jcpe.13079.

Mazzocco, F., Nart, J., Cheung, W. S., Griffin, T. J. (2011). Prospective evaluation of the use of motorized ridge expanders in guided bone regeneration for future implant sites. International Journal of Periodontics and Restorative Dentistry. Sep-Oct;31(5):547-54. 
Meloni, S. M., Jovanovic, S. A., Urban, I., Canullo, L., Pisano, M., Tallarico, M. (2017). Horizontal ridge augmentation using GBR with a native collagen membrane and 1:1 ratio of particulated xenograft and autologous bone: a 1-year prospective clinical study. Clinical Implant Dentistry and Related Research. Feb;19(1):38-45. doi: 10.1111/cid.12429

Mengel, R., \& Flores-de-Jacoby, L. (2005). Implants in regenerated bone in patients treated for generalized aggressive periodontitis: A prospective longitudinal study. International Journal of Periodontics and Restorative Dentistry. Aug;25(4):331-41.

Mir-Mari, J., Wui, H., Jung, R. E., Hämmerle, C. H., Benic, G. I. (2016). Influence of blinded wound closure on the volume stability of different GBR materials: an in vitro cone-beam computed tomographic examination. Clinical Oral Implants Research. Feb;27(2):258-65. doi: $10.1111 / \mathrm{clr} .12590$.

Naenni, N., Lim, H. C., Papageorgiou, S. N., Hammerle, C.H.F. (2019). Efficacy of lateral bone augmentation prior to implant placement: a systematic review and meta-analysis. Journal of Clinical Periodontology. Jun;46 Suppl 21:287-306. doi: 10.1111/jcpe.13052.

Pitaru, S. Tal, H., Soldinger, M., Azar-Avidan, O., Noff, M. (1987) Collagen membranes prevent the apical migration of epithelium during periodontal wound healing. Journal of Periodontal Research. Jul;22(4):331-3.

Schenk, R. K., Buser, D., Hardwick, W. R., Dahlin, C. (1994). Healing pattern of bone regeneration in membrane-protected defects: a histologic study in the canine mandible. International Journal of Oral and Maxillofacial Implants. Jan-Feb;9(1):13-29.

Schropp, L., Wenzel, A.,, Kostopoulos, L., Karring, T. (2003). Bone healing and soft tissue contour changes following single-tooth extraction: a clinical and radiographic 12-month prospective study. International Journal of Periodontics and Restorative Dentistry. Aug;23(4):313-23.

Simon, B.I., Chiang, T.F., Drew H.J. (2010). Alternative to the gold standard for alveolar ridge augmentation: tenting screw technology. Quintessence International. May;41(5):379-86.

Tan, W. L., Wong, T.L., Wong, M. C., Lang, N. P. (2012). A systematic review of post-extractional alveolar hard and soft tissue dimensional changes in humans. Clinical Oral Implants Research. Feb;23 Suppl 5:1-21. doi: 10.1111/j.1600-0501.2011.02375.x.

This article is protected by copyright. All rights reserved 
Zitzmann, N.U., Naef, R. \& Scharer, P. (1997) Resorbable versus nonresorbable membranes in combination with Bio-Oss for guided bone regeneration. The International Journal of Oral and Maxillofacial Implants. 12: 844-852.

Zitzmann, N. U., Scharer, P. \& Marinello, C. P. (2001) Long-term results of implants treated with guided bone regeneration: a 5-year prospective study. The International Journal of Oral and Maxillofacial Implants. 16, 355-366.

This article is protected by copyright. All rights reserved 
TABLE 1 Edentulous sites evaluated, divided by tooth types in each group.

\begin{tabular}{lcccc|cccc} 
& & \multicolumn{1}{c}{$\begin{array}{c}\text { Test } \\
(\mathrm{n}=22)\end{array}$} & & \multicolumn{3}{c}{$\begin{array}{c}\text { Control } \\
(\mathrm{n}=22)\end{array}$} \\
& Incisors & Canines & Premolars & Molars & Incisors & Canines & Premolars & Molars \\
\hline Maxila & 5 & 1 & 3 & 0 & 9 & 1 & 2 & 0 \\
Mandibule & 0 & 0 & 5 & 8 & 1 & 0 & 3 & 6 \\
\hline
\end{tabular}

This article is protected by copyright. All rights reserved 
TABLE 2 Mean and standard deviation $( \pm S D)$ of the ridge width $(R W)$ in $(\mathrm{mm})$ at 1,3,5 and $7 \mathrm{~mm}$ apical of the bone crest at baseline.

$\begin{array}{ccccc}\begin{array}{c}\text { Ridge Width at } \\ \text { Baseline }\end{array} & \begin{array}{c}\text { Test } \\ (\boldsymbol{n}=\mathbf{2 2})\end{array} & \begin{array}{c}\text { Control } \\ (\boldsymbol{n}=\mathbf{2 2})\end{array} & \begin{array}{c}\text { Difference } \\ \text { between the } \\ \text { groups }\end{array} & \text { p value } \\ \text { RW-1 } & 3.18 \pm 1.57 & 3.28 \pm 1.53 & 0.10 \pm 0.07 & 0.320 \\ \text { RW-3 } & 5.06 \pm 2.44 & 5.01 \pm 1.63 & 0.06 \pm 0.04 & 0.734 \\ \text { RW-5 } & 6.89 \pm 3.14 & 6.05 \pm 2.15 & 0.84 \pm 0.59 & 0.346 \\ \text { RW-7 } & 8.37 \pm 3.47 & 7.10 \pm 2.54 & 1.28 \pm 0.90 & 0.178 \\ \text { Overall } & \mathbf{5 . 8 7} \pm \mathbf{2 . 4 1} & \mathbf{5 . 3 6} \pm \mathbf{1 . 6 5} & \mathbf{0 . 5 1} \pm \mathbf{0 . 3 7} & \mathbf{0 . 5 5 5}\end{array}$

Note. $n$ : number of sites; $R W$-1: ridge width $1 \mathrm{~mm}$ apical of the bone crest; $R W$-3: ridge width $3 \mathrm{~mm}$ apical of the bone crest; $R W-5$ : ridge width $5 \mathrm{~mm}$ apical of the bone crest; $R W-7$ : ridge width $7 \mathrm{~mm}$ apical of the bone crest.

This article is protected by copyright. All rights reserved 
TABLE 3 Mean and standard deviation $( \pm S D)$ of the ridge width $(R W)$ in $(\mathrm{mm})$ at 1,3,5 and $7 \mathrm{~mm}$ apical of the bone crest at follow-up.

$\begin{array}{ccccc}\begin{array}{c}\text { Ridge Width at } \\ \text { Follow-up }\end{array} & \begin{array}{c}\text { Test } \\ (\boldsymbol{n}=\mathbf{2 2})\end{array} & \begin{array}{c}\text { Control } \\ (\boldsymbol{n}=\mathbf{2 2})\end{array} & \begin{array}{c}\text { Difference } \\ \text { between the } \\ \text { groups }\end{array} & \boldsymbol{p} \text { value } \\ \text { RW-1 } & 6.90 \pm 2.99^{*} & 4.54 \pm 2.62^{*} & 2.36 \pm 1.67 & 0.004^{*} \\ \text { RW-3 } & 9.03 \pm 2.52^{*} & 7.51 \pm 2.11^{*} & 1.52 \pm 1.02 & 0.022^{*} \\ \text { RW-5 } & 10.65 \pm 3.03^{*} & 9.00 \pm 1.91^{*} & 1.65 \pm 1.17 & 0.047^{*} \\ \text { RW-7 } & 11.30 \pm 3.34 & 9.78 \pm 2.26 & 1.52 \pm 1.07 & 0.129 \\ \text { Overall } & \mathbf{9 . 4 7} \pm \mathbf{2 . 6 3 ^ { * }} & \mathbf{7 . 7 0} \pm \mathbf{1 . 8 5}^{*} & \mathbf{1 . 7 7} \pm \mathbf{1 . 2 3} & \mathbf{0 . 0 1 0}^{*}\end{array}$

Note. $n$ : number of sites; $R W$-1: ridge width $1 \mathrm{~mm}$ apical of the bone crest; $R W$-3: ridge width $3 \mathrm{~mm}$ apical of the bone crest; $R W-5$ : ridge width $5 \mathrm{~mm}$ apical of the bone crest; $R W$-7: ridge width $7 \mathrm{~mm}$ apical of the bone crest; *Significantly different between groups, $p<0.05$.

This article is protected by copyright. All rights reserved 
TABLE 4 Mean and standard deviation $( \pm S D)$ for Ridge Width change (RWchange) in $(\mathrm{mm})$ measured at $1,3,5$ and $7 \mathrm{~mm}$ apical of the bone crest.

\begin{tabular}{ccccc} 
Ridge Width change & $\begin{array}{c}\text { Test } \\
(\boldsymbol{n}=\mathbf{2 2})\end{array}$ & $\begin{array}{c}\text { Control } \\
(\boldsymbol{n}=\mathbf{2 2})\end{array}$ & $\begin{array}{c}\text { Difference } \\
\text { between the } \\
\text { groups }\end{array}$ & $\boldsymbol{p}$ value \\
\hline RWchange-1 & $3.72 \pm 2.46^{*}$ & $1.25 \pm 3.05^{*}$ & $2.50 \pm 1.75$ & $0.001^{*}$ \\
RWchange-3 & $3.98 \pm 2.53^{*}$ & $2.50 \pm 2.02^{*}$ & $1.47 \pm 0.69$ & $0.020^{*}$ \\
RWchange-5 & $3.75 \pm 2.29$ & $2.94 \pm 1.95$ & $0.81 \pm 0.57$ & 0.416 \\
RWchange-7 & $2.92 \pm 2.15$ & $2.68 \pm 2.43$ & $0.24 \pm 0.17$ & 0.986 \\
Overall & $\mathbf{3 . 5 7} \pm \mathbf{2 . 3 8 ^ { * }}$ & $\mathbf{2 . 3 5} \pm \mathbf{1 . 6 4}$ & $\mathbf{1 . 2 2} \pm \mathbf{0 . 8 6}$ & $\mathbf{0 . 0 0 9}^{*}$
\end{tabular}

Note. $n$ : number of sites; $R W$ change-1: ridge width change $1 \mathrm{~mm}$ apical of the bone crest; $R W$ change-3: ridge width change $3 \mathrm{~mm}$ apical of the bone crest; ; RWchange-5: ridge width change $5 \mathrm{~mm}$ apical of the bone crest; RWchange7: ridge width change $7 \mathrm{~mm}$ apical of the bone crest; *Significantly different between groups, $p<0.05$.

This article is protected by copyright. All rights reserved 
TABLE 5 Descriptive analysis by Mean and standard deviation ( $\pm S D$ ) of Lingual Rigde Width Change (LRWchange) in ( $\mathrm{mm}$ ) at 1,3,5 and $7 \mathrm{~mm}$ apical of the bone crest at follow-up.

\begin{tabular}{cc}
\hline & LRWchange $(\boldsymbol{n}=\mathbf{1 9})$ \\
\hline LRWchange-1 & $0.54 \pm 1.0$ \\
\hline LRWchange-3 & $1.15 \pm 0.81$ \\
\hline LRWchange-5 & $1.03 \pm 0.72$ \\
\hline LRWchange-7 & $1.03 \pm 1.47$ \\
\hline Overall & $\mathbf{0 . 9 4} \pm \mathbf{1 . 0 0}$ \\
\hline
\end{tabular}

This article is protected by copyright. All rights reserved 
TABLE 6 Comparison between the groups regarding primary outcome through multilevel linear regression analysis.

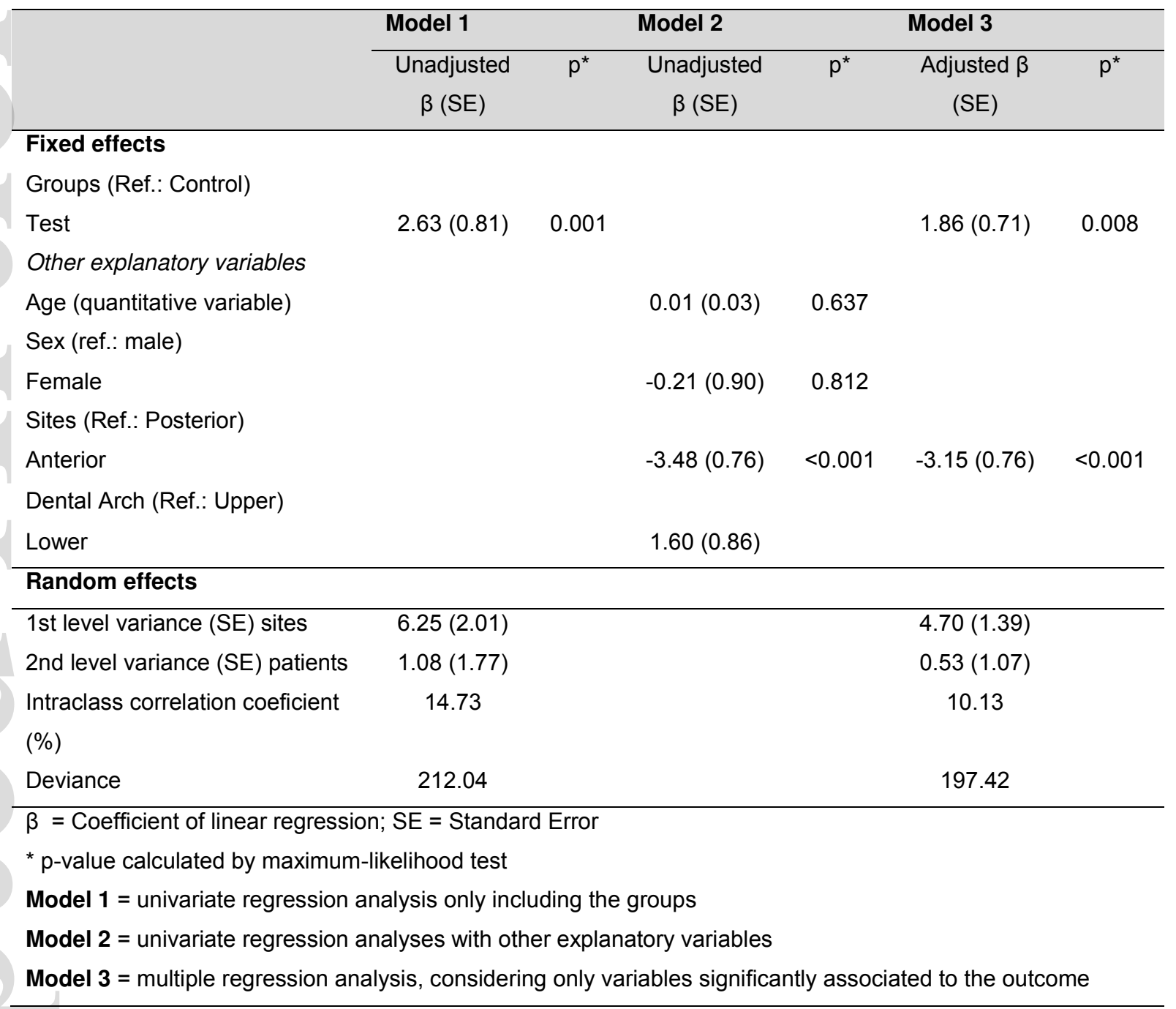

This article is protected by copyright. All rights reserved 


\section{FIGURE LEGENDS}

Fig. 1. Photographs illustrating a clinical case of TS group. Full-thickness trapezoidal flap with a linear incision at the mid-crest and two releasing incisions one-tooth apart of bone defect and decorticalization (a) were performed. The screw was inserted at the center of horizontal defect, with the coronal portion of the screw head about $1 \mathrm{~mm}$ below the top of the ridge and $4 \mathrm{~mm}$ out of buccal bone (a)(b). Bone defects were grafted with DBBM and covered with a collagen membrane (c). Simple interrupted sutures were placed in the releasing incisions and in the horizontal incision, horizontal mattress sutures were placed only in the horizontal incision (d).

Fig. 2. Schematic illustration of measurements performed before and after augmentation procedure. A grid was inserted at the baseline image with a vertical line (VL) at the center of alveolar ridge. For the vertical gain or resorption (dashed purple line), measurements were performed using the vertical line as reference from the bottom (resorption) or the top of the bone (gain), when compared to the bone crest level at baseline. Five horizontal lines at bone crest, 1, 3, 5 and $7 \mathrm{~mm}$ below the bone crest. After superimposition, the grid was inserted at the same region of interest. Ridge width was measured from the lingual/palatal cortical bone to the buccal cortical bone at baseline (red line) and after augmentation (red line plus dashed blue line). Ridge width change (RWchange) was considered the difference between RW at baseline and after augmentation (dashed blue lines).

Fig. 3. Cone-beam computed tomography at baseline (a,c) and after augmentation (b,d) for Test group (a,b) and Control group (c, d). 


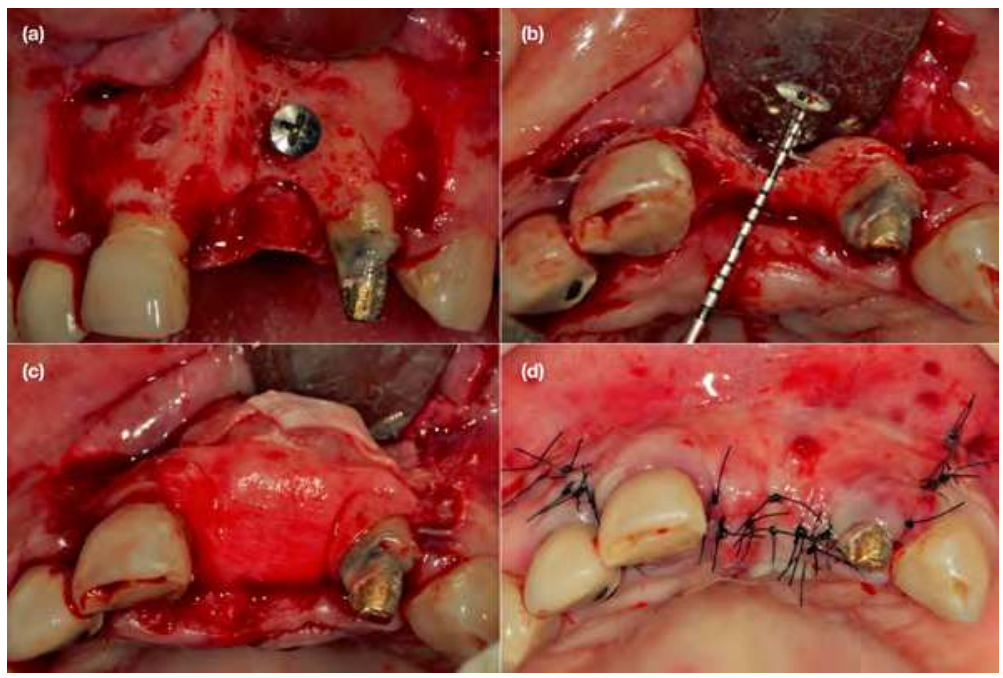

clr_13630_f1.tiff 

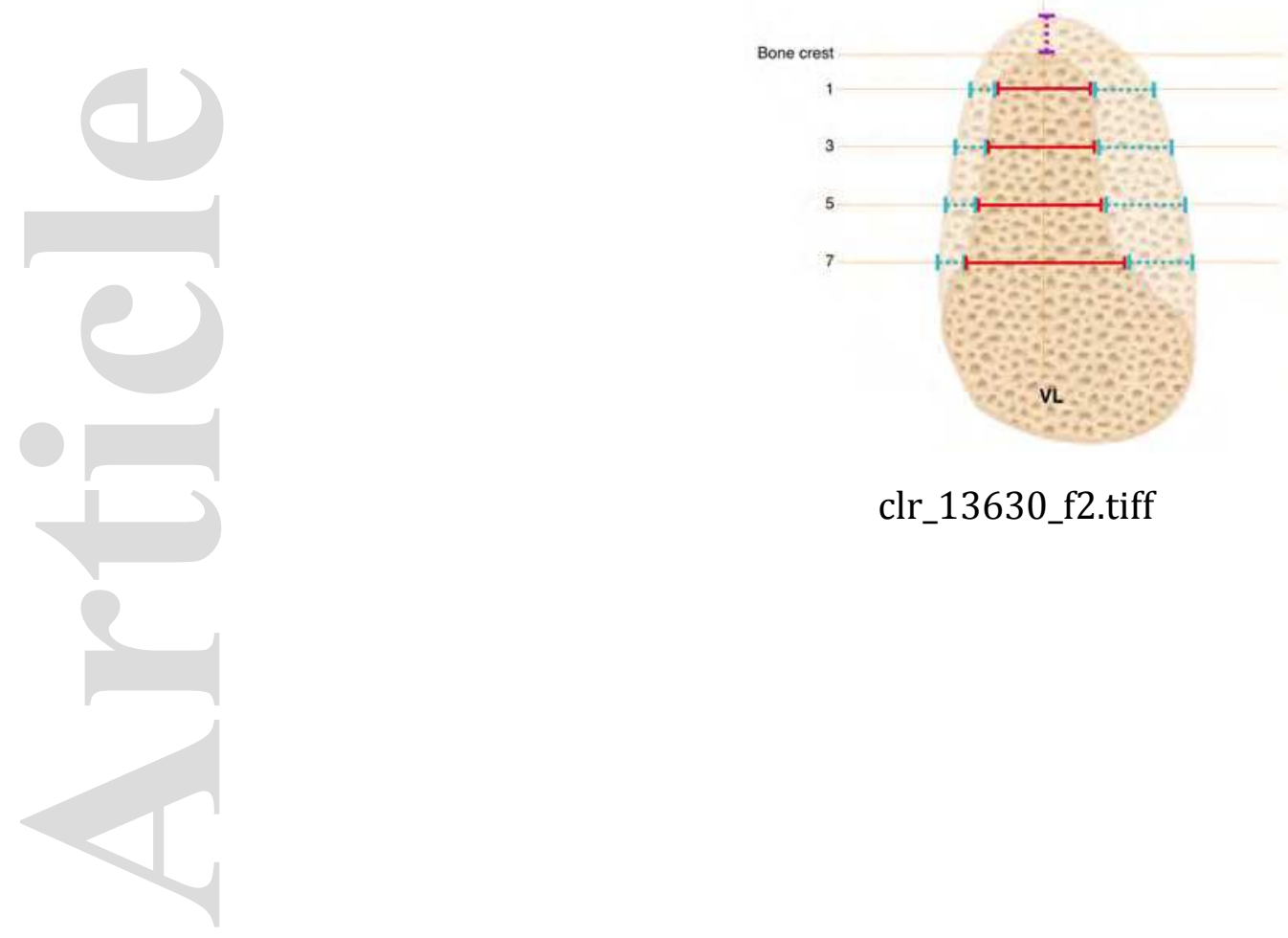

clr_13630_f2.tiff

This article is protected by copyright. All rights reserved 

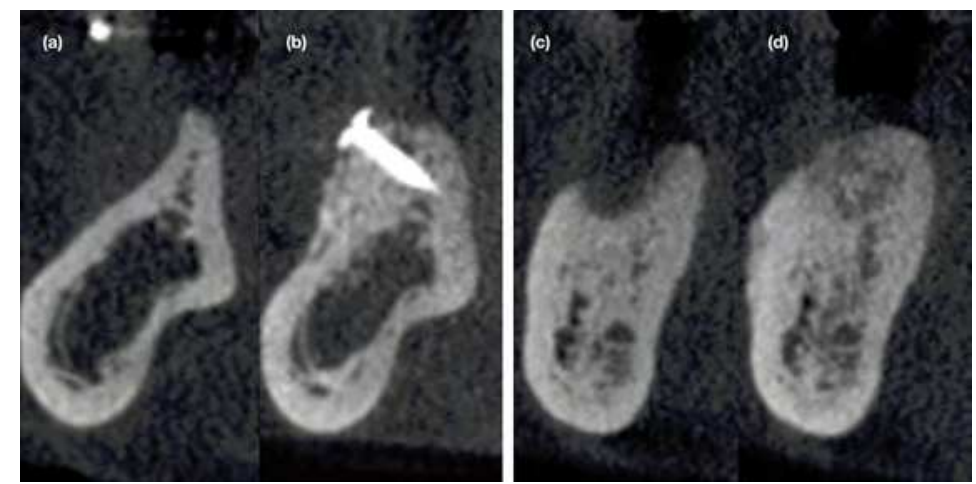

clr_13630_f3.tiff 